\title{
Assess the Effectiveness of protective Concrete coatings of microbiological sulfuric acid Aggression
}

\author{
Viktor Sopov ${ }^{*}$, Julia Danchenko and Ekaterina Latorez \\ Kharkiv National University of Civil Engineering and Architecture, Faculty of Mechanics and \\ Technology, Sumskaya str., 40, Kharkiv, 61002, Ukraine
}

\begin{abstract}
Specification of corrosion processes in sewerage networks, the predominant role of microbiological processes in them requires the protection of concrete with materials resistant to specific biogenic sulfuric acid aggression. The effective protective materials, in this case, are those that, in addition to acid-proofing materials, have bactericidal properties. Polymer composite materials (PCM) of cold curing based on modified epoxy-resin, resins with dispersed oxides as fillers are widely used in construction. Unique properties and simple technologies make it possible to use them as injection formulations for repair, restoration and restoration of building structures and structures, waterproofing and facing materials, for impregnating, gluing and coating metal, wooden, brick and concrete building structures and parts. In the reconstruction and restoration of sewerage collectors operating under conditions of exposure to liquid biochemically aggressive media with mineral acids and organic substances, particular attention is paid to the permeability of repair materials. Based on the results of the study, PCM compositions were chosen whose estimated lifetime is about 20 years, ensuring reliable protection of the sewage collectors from corrosion.
\end{abstract}

\section{Introduction}

To effectively protect the concrete sewage collectors ceramic tiles are used. It has a low permeability and resistance to the action of chemically active substances. However, in this technology there is one significant drawback - joints between tiles remain permeable to aggressive chemicals and bacteria. Specification of corrosion processes in sewerage networks and the predominant role of microbiological processes in them require the protection of concrete with materials resistant to specific biogenic sulfuric acid aggression [1-2]. The effective protective materials in this case are those, which, in addition to acidproofing materials, also possess bactericidal properties. The most resistant to biochemical aggression are composites based on epoxydian resins [3-4]. The complex multicomponent composition of such compositions requires careful study of their properties for obtaining stable and effective protective materials.

\footnotetext{
* Corresponding author: vsopov@ukr.net
} 


\section{Materials and methods of research}

Composite materials (CM) for low-temperature curing contain epoxydian resin (ED-20), polyamine-oligoamide (L-20), polyethylene polyamine (PEPA), non-inorganic surfactant (Amirol $\mathrm{M}$ ) and clay acid-resistant tile filler (GP) as a filler. The CM without filler (BEK) and filler (BTEK) were investigated.

Acid-resistant tile clay (GP) is a mixture of natural minerals: it consists of $\mathrm{SiO}_{2}(55-$ $65 \%), \mathrm{Al}_{2} \mathrm{O}_{3}(18-20 \%), \mathrm{Fe}_{2} \mathrm{O}_{3}(2,2-3 \%), \mathrm{MgO}$ (1,5-2\%), $\mathrm{CaO}$ (3,5-4\%). Acid-resistant tile clay - clay dispersed mixture of brick-red color for the manufacture of ceramic acidresistant tiles. It is characterized by a polymineral composition with predominant phases of kaolinite $\mathrm{Al}_{2} \mathrm{Si}_{2} \mathrm{O}_{5}(\mathrm{OH})_{4}$ and hydromica $(\mathrm{K}, \mathrm{Na}) \mathrm{Al}_{2}(\mathrm{Si}, \mathrm{Al})_{4} \mathrm{O}_{10}(\mathrm{OH})_{2} \mathrm{nH}_{2} \mathrm{O}$. The concomitant phases are $\beta$-quartz $\mathrm{SiO}_{2}$, albite $\mathrm{NaAlSi}_{3} \mathrm{O}_{8}$, microcline $\mathrm{KAlSi}_{3} \mathrm{O}_{8}$ and hornblende $(\mathrm{Na}, \mathrm{K}) \mathrm{Ca}_{2}(\mathrm{Fe}, \mathrm{Mg})_{5}(\mathrm{Al}, \mathrm{Si})_{8} \mathrm{O}_{22}(\mathrm{OH})_{2}$. Epoxy mastics and coatings with the addition of GP are characterized by chemical and biological resistance and high adhesion to concrete, glass, wood and metal surfaces and as well as durability.

Investigation of the particles surface morphology of the filler was carried out using electron microscopic images made with a scanning microscope of the brand JSM-6390LV. The thermal analysis of the samples was carried out using the SDT Q600 derivatograph from TA Instruments (USA). To analyze the microporous compositions the thermoporometry method based on differential scanning calorimetry was used [5].

\section{Results of the research}

The results of electron microscopic studies of the filler particles morphology are shown in Fig. 1.

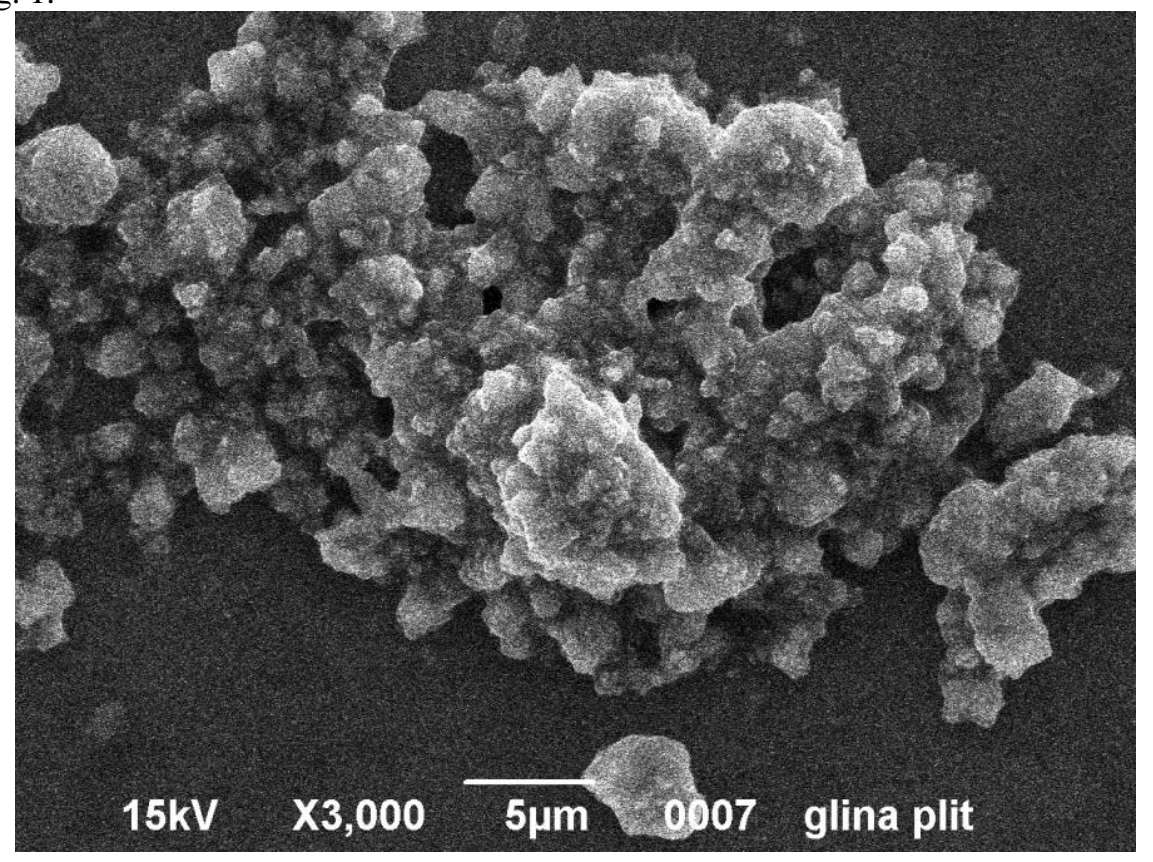

Fig. 1. Morphology of the filler particles.

One can see from Fig. 1, clay particles have a conventionally spherical shape and are prone to association. This is confirmed by the results of studying the structural and rheological and surface characteristics of the filler. Thus, at a true density $\rho=1807 \mathrm{~kg} / \mathrm{m}^{3}$, 
the bulk density is almost 5 times greater and equal to $\rho_{\mathrm{b}}=382 \mathrm{~kg} / \mathrm{m}^{3}$, and the interparticle friction index $\mathrm{I}=1.999$. It was also found that the BET specific surface area $(\mathrm{S}=15.0$ $\left.\mathrm{m}^{2} / \mathrm{g}\right)$ is 30 times higher than its value $\left(\mathrm{S}=0.5 \mathrm{~m}^{2} / \mathrm{g}\right)$ determined by the Tovarov method.

The thermal analysis of the samples under study (Fig. 2) shows the presence of endothermic dehydration effects (removal of physically bound water molecules from the surface) to $300{ }^{\circ} \mathrm{C}$ and dehydroxylation (removal of chemically bound water in the form of surface hydroxyl groups) in the high-temperature region $300-900^{\circ} \mathrm{C}$. The calculated fraction of physically bound water is $\sim 3.3 \%$, and chemically bound about $7.0 \%$ of the sample mass. A fairly large amount of physically adsorbed water on the surface of the particles is apparently due to the presence of $\mathrm{CaO}$ and $\mathrm{MgO}$ and hydromica in the composition. Chemically bound water is present in some minerals (kaolinite, hydromica, hornblende) and as found to be abundant on the surface of the particles as hydroxyl groups.

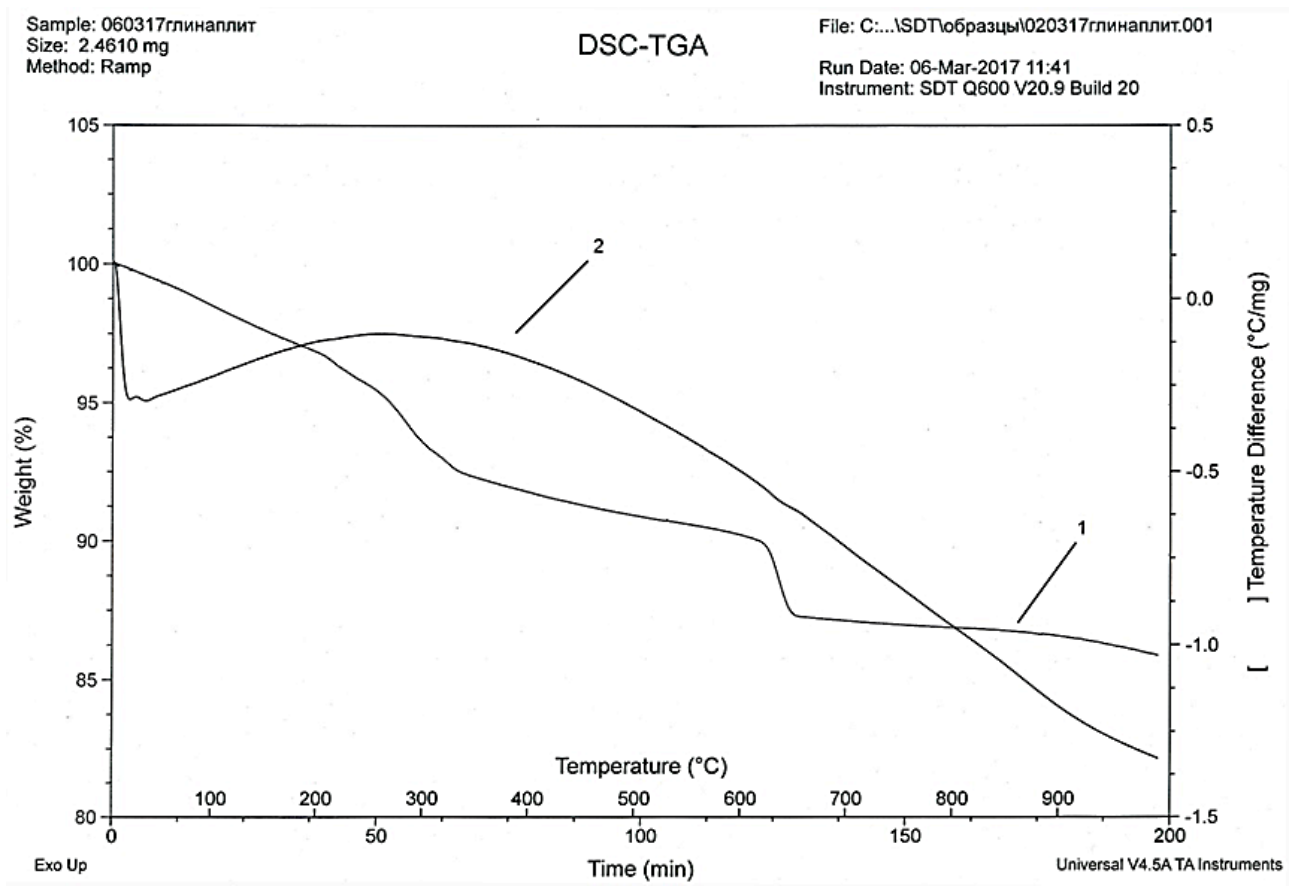

Fig. 2. Thermal analysis of samples 1 - TG; 2 - DTA.

By the method of adsorption of Hammett color indicators from aqueous solutions [6], the amount and acid-base force of the active centers (hydroxyl groups) on the surface of the GP were determined. It is established that strongly basic centers with $\mathrm{pKa}=+10.5$ prevail on the surface. Their share is about $80 \%$ of all detected. The rest of the centers are weakly acidic with $\mathrm{pKa}=+5.0$. Thus, the GP surface has a strongly basic character, which is confirmed by the acidity index of the aqueous extract of the filler, which is $\mathrm{pH}=10.1$.

The introduction of GP into the composition promotes the formation of a more rigid structure and an increase in the concentration of the cured polymer mesh points. This is evidenced by a decrease in the molecular weight of the interstitial fragment of the network $\left(\mathrm{M}_{\mathrm{c}}\right)$, the relative strain in the elastomeric state $\left(\varepsilon_{\mathrm{n}}\right)$, and the temperature interval for the transition to the highly elastic region $\left(\Delta \mathrm{T}=\mathrm{T}_{\mathrm{BE}}-\mathrm{T}_{\mathrm{c}}\right)$ (Table 1$)$. 
Table 1. Physical and chemical properties of compositions.

\begin{tabular}{|l|l|l|}
\hline \multicolumn{1}{|c|}{ Index } & \multicolumn{1}{|c|}{ BEK } & \multicolumn{1}{c|}{ BTEK-1 } \\
\hline The diffusion coefficient of $\mathrm{H}_{2} \mathrm{O}$ at $298 \mathrm{~K}, \mathrm{D} \cdot 10^{9}, \mathrm{sm}^{2} / \mathrm{c}$ & 6,89 & 6,16 \\
\hline $\begin{array}{l}\text { The diffusion coefficient of } \mathrm{H}_{2} \mathrm{SO}_{4}(10 \%) \text { at } 298 \mathrm{~K}, \mathrm{D} \cdot 10^{9}, \\
\mathrm{~cm}^{2} / \mathrm{c}\end{array}$ & 6,98 & 6,90 \\
\hline Glass transition temperature, $\mathrm{T}_{\mathrm{c}}, \mathrm{K}$ & 343 & 342 \\
\hline The transition interval to the highly elastic region, $\Delta \mathrm{T}, \mathrm{K}$ & 13,0 & 9,0 \\
\hline$\varepsilon_{\mathrm{rel}}, \%$ & 10,3 & 7,0 \\
\hline $\mathrm{M}_{\mathrm{c}}, \mathrm{kg} /$ mole & 1460 & 1250 \\
\hline
\end{tabular}

Obviously, the formation of a more rigid polymer structure is associated with an increase in the intermolecular interaction, and possibly with the catalytic effect of active surface centers on the curing process. The strongly basic nature of the filler surface presupposes acid-base interactions between the adsorption centers of the surface and the hydroxyl groups of the epoxy-resin molecules, which have a weak acid reaction. The weak acid nature of these $\mathrm{OH}$ groups is determined by the fact that they are the main cause of autocatalytic reactions during the curing of epoxyamine compositions. In addition, in the presence of Amirol M - a non-ionic surfactant in the composition, molecules of which has two types of hydroxyl groups (weakly acidic and weakly basic), the increase in intermolecular interaction in the system is also evident.

Amirol M:

$$
\begin{array}{r}
\mathrm{R}-\mathrm{C}-\mathrm{N}-\mathrm{CH}_{2}-\mathrm{CH}_{2}-\mathrm{OH} \\
\mathrm{CH}_{2}-\mathrm{CH}_{2}-\mathrm{OH}
\end{array}
$$

where $\mathrm{R}=\mathrm{C}_{18}$ (residue of recinolic acid).

A more rigid and dense structure of the polymer can be one of the reasons for the reduction of diffusion coefficients of water and an aqueous $10 \%$ solution of sulfuric acid. Thus, the addition of GP promotes a decrease in the permeability of the cured polymer for distilled water by $11 \%$, and for the $\mathrm{H}_{2} \mathrm{SO}_{4}$ solution by $2 \%$ (Table 1 ).

When epoxyamine compositions are modified with dispersed fillers, in most cases an increased concentration of macrodefects in the form of pores and cracks is observed. The appearance of such defects is due to the incomplete wetting of the polymer filler surface, the concentration of internal stresses, and the easier emergence of gas bubbles at the interface. This is contradicted by the experimental data obtained to determine the microporosity of the compositions by the thermoporometry method (Fig. 3).

The micropore distribution by size shows (Fig. 3, a) that the unfilled epoxy-amine composition of BEK is characterized by the presence of three regions of distribution with maxima at $6,3.3$ and $2.7 \mathrm{~nm}$. For BTEK, there are also three regions of micropores with distribution maxima at 6, 3.6, and $3 \mathrm{~nm}$. In this case, the volume of micropores (Fig. 3, b) of the BTEK composition decreases by a factor of 10 compared to BEK.

Reducing the size and volume of micropores indicates a decrease in the permeability of such compositions, since a decrease in pore sizes leads to the change in the properties of pore water and the mechanization of the matter transfer [7]. The observed micropores are characterized by a mechanism based on molecular diffusion, which, under the conditions of the pore fluid structure, will be difficult.

In addition, a decrease in the total volume of micropores indicates the discreteness of their distribution in the structure of the composition, which undoubtedly also sharply reduces permeability. 


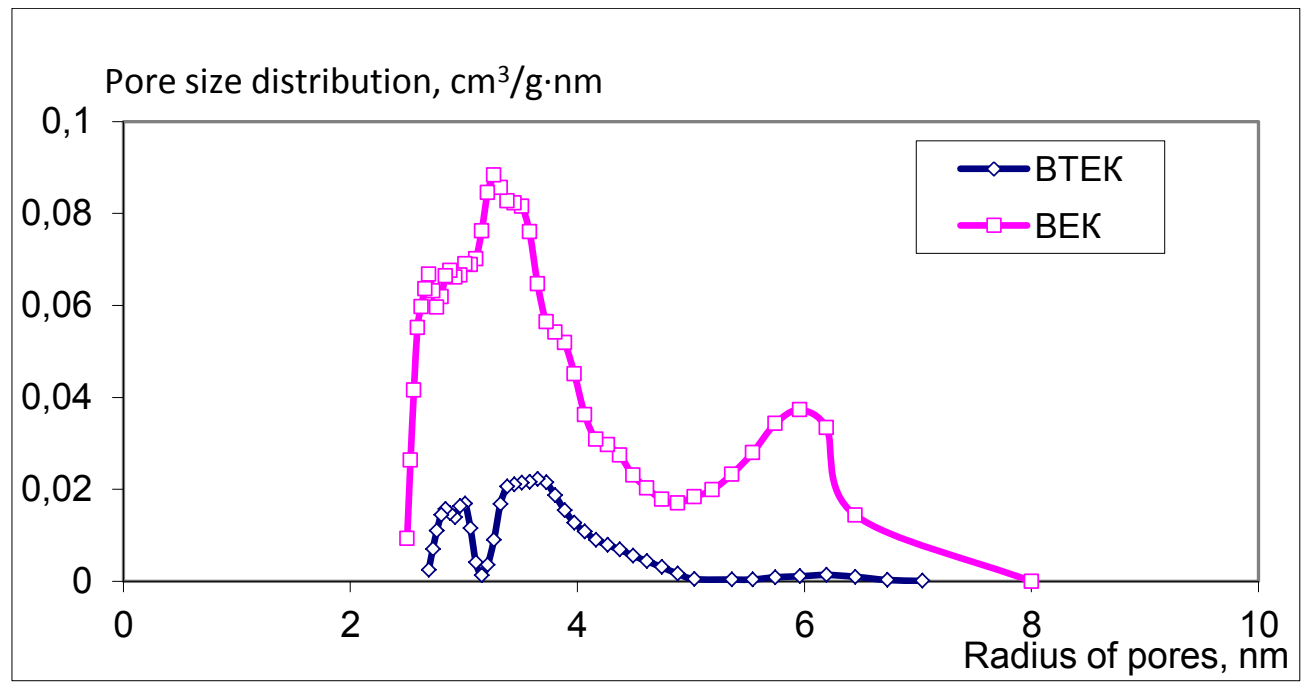

a)

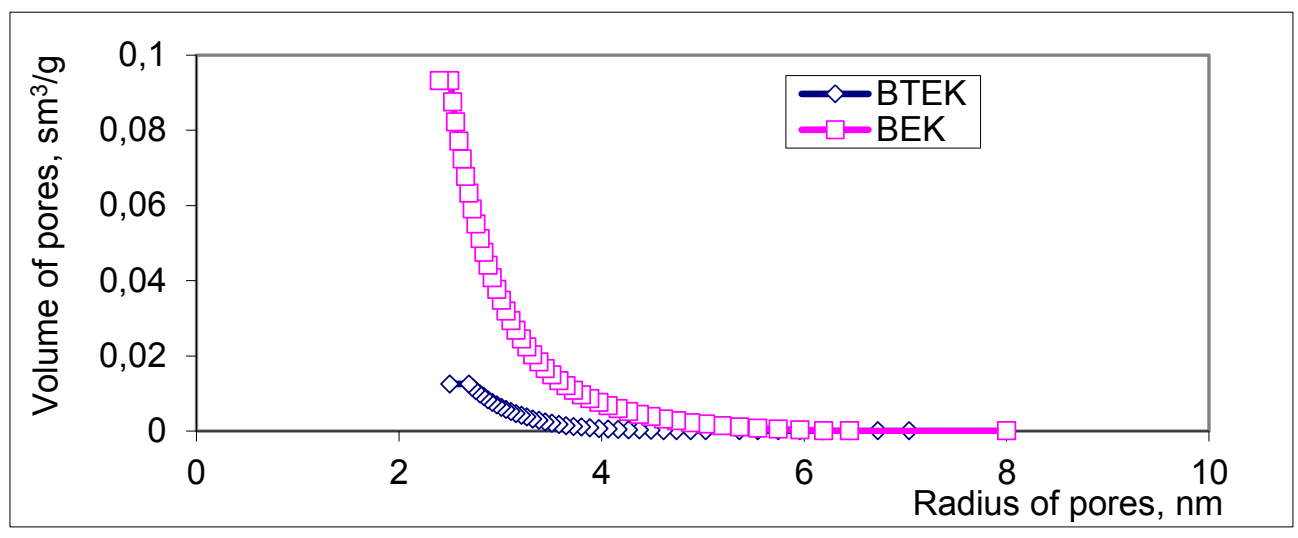

b)

Fig. 3. Microporosity of epoxyamine compositions a) pore size distribution, b) volume of pores.

Standard tests of water permeability of concrete samples showed that for the mark on water permeability of control sample W6, the coated samples from the developed compositions had the W12 mark.

\section{Discussion of the results}

From the obtained research results, it follows that in these compositions, good wettability, as well as a decrease in internal stresses, are obviously ensured by the presence of a surfactant molecules of which are adsorbed on the filler surface by an acid-base mechanism, thereby providing increased segmental mobility of molecules and a relaxing ability of polymer.

The epoxy coating of BTEK ensures the preservation of alkaline medium in concrete ( $\mathrm{pH}$ 8) and, accordingly, prevents the diffusion of sulfuric acid. The state of concrete samples coated with BTEK coating can be determined as good: in general, the samples are 
practically unaffected, only a slight delamination of the coating from the edges (5\%) is observed.

In addition, it was found that the aggressive environment of the reservoir contributes to the formation of a more rigid structure of the epoxy polymer. It is evidenced by an increase in the glass transition temperature and a decrease in the molecular mass of the interstitial fragment of the chain $\left(\mathrm{M}_{\mathrm{c}}\right)$ and the relative deformation $\left(\varepsilon_{\mathrm{rel}}\right)$.

Strengthening the structure of the epoxy polymer network is associated with the process of pre-cure, catalyzed by protons of sulfuric acid, penetrating into the volume of the polymer.

For the preparation and application of bactericidal epoxy mastic, a technological process was developed for sealing joints lined with acid-resistant shaped ceramic tiles, reinforced concrete disposal facilities.

The estimated life of such composition is about 20 years, ensuring reliable protection of the sewage collectors from corrosion.

\section{Conclusions}

Summarizing the results of laboratory experiments, it can be concluded that the epoxy compositions studied have bactericidal properties and can be used as protective coatings for building structures exposed to biologically aggressive acid media. The introduction of a mineral acid-resistant filler into the composition makes it possible to increase the inhibitory properties of the composition that contributes to a decrease in the activity of the bacteria and, possibly, their death.

The developed mastics have good resistance in liquid aggressive media, adhesive strength in comparison with known compositions recommended by regulatory documents for repair and restoration of reinforced concrete sewage collectors from biochemical corrosion. This allows us to recommend the developed bactericidal epoxy amine compositions for the protection and repair of reinforced concrete sewage collectors.

\section{References}

1. B. Jay, Schrock. Existing Sewer Evaluation and Rehabilitation. Water Environment Federation. ASCE, 262 (1994)

2. Marjorie Valix, Diyana Zamri, Hiro Mineyama, Wai Hung Cheung, Jeffrey Shi and Heri Bustamante, Chinese Journal of Chemical Engineering, 20 (3), (2012)

3. E. Vincke, E. Van Wanseele, International Biodeterioration \& Biodegradation, 49, 4, (2002)

4. W. Kaempfer and Berndt M., Proc. of the IX ICPIC Congress, Bologna, Italy, (1998)

5. A.V. Usherov-Marshak, V.P. Sopov, Journal of Therm. Analysis, 43, 2, (1995)

6. L. P. Hammett, A. J. Deyrup, J. Am. Chem. Soc., 54, (1932)

7. K.S. Basniev, N.I. Kochina, M.V. Maksimov. Underground hydromechanics (Moscow: Nedra, 1993) 